\title{
Identification of new risk factors for pneumonia: population-based case-control study
}

\author{
Yana Vinogradova, Julia Hippisley-Cox and Carol Coupland
}

\begin{abstract}
Background

Certain conditions are established as risk factors for community-acquired pneumonia. There are a number of other conditions that may also be risk factors, but information on these is limited.
\end{abstract}

Aim

To determine new independent risk factors for community-acquired pneumonia using a very large primary care database.

Design of study

Nested case-control study.

Setting

Four hundred and forty-three general practices in the UK contributing to the QRESEARCH database.

\section{Method}

A total of 17172 incident cases of all ages diagnosed with pneumonia between 1996 and 2005 were matched with up to five controls by age, sex, general practice, and calendar year. Associations between pneumonia and each established condition and potential risk factors were determined with odds ratios (ORs), using multiple conditional logistic regression analysis adjusted for smoking, socioeconomic status, and use of influenza and pneumococcal vaccines.

\section{Results}

The analysis confirmed the higher risk of pneumonia among patients with at least one of the established risk factors; the adjusted OR was 2.29 (95\% confidence interval $[\mathrm{Cl}]=2.20$ to 2.39 ). In addition, patients with the following conditions had a higher risk of pneumonia despite adjustment for known risk factors and confounders: stroke or transient ischaemic attack, rheumatoid arthritis, Parkinson's disease, cancers, multiple sclerosis, dementia, and osteoporosis. The adjusted OR for pneumonia among patients without an established risk factor but with at least one of the new conditions was $2.44(95 \% \mathrm{Cl}=2.24$ to 2.65$)$.

\section{Conclusion}

As well as confirming some established risk factors, this study has determined seven new independent risk factors for community-acquired pneumonia.

\section{Keywords}

pneumonia; population; risk factors.

\section{INTRODUCTION}

Community-acquired pneumonia is a serious condition, which affects annually up to 11 per 1000 adults, ${ }^{1}$ and up to 40 per 1000 of children. ${ }^{2}$ Of these, almost half require hospital admission. Streptococcus pneumoniae is the commonest cause of communityacquired pneumonia and can be fatal in up to $20 \%$ of cases. $^{3}$

While pneumonia can affect any age group, at most risk are adults aged $\geq 65$ years, and infants and young children, who do not have a fully developed immune system. Patients at risk include those with splenic dysfunction, ${ }^{4}$ cochlear implants or cerebrospinal fluid shunts, ${ }^{3}$ chronic cardiovascular disease, chronic pulmonary disease, diabetes, ${ }^{5}$ chronic liver disease, ${ }^{6-8}$ and chronic renal failure, ${ }^{5,9}$ as well as those with HIV and AIDS. ${ }^{10,11}$ The 23-valent pneumococcal immunisation has been recommended since 1992 for individuals at high risk of invasive pneumococcal disease, and in 2003 the recommendation was extended to include all people aged $\geq 65$ years. Pneumococcal vaccination rates have increased over time as a consequence. ${ }^{12}$ However, there might be other patients who are at increased risk of pneumonia with conditions that are not included in the vaccine guidelines. Equally, some of those in established risk groups included in the guidelines may not actually be at high risk, since evidence is limited for some of the

Y Vinogradova, MSc, research statistician; J Hippisley-Cox, $M D, P h D$, professor of clinical epidemiology and general practice; C Coupland, PhD, associate professor in medical statistics, Division of Primary Care, University of Nottingham, Nottingham.

Address for correspondence

Y Vinogradova, Division of Primary Care, University of Nottingham, University Park, Nottingham NG7 2RD.

E-mail: yana.vinogradova@nottingham.ac.uk

Submitted: 1 February 2009; Editor's response: 15 May 2009; final acceptance: 18 June 2009.

(C) British Journal of General Practice

This is the full-length article of an abridged version published in print. Cite this article as: Br J Gen Pract 2009; DOI: 10.3399/bjgp09X472629. 
specified risk groups. Patients with rheumatoid arthritis, for example, are not included in the guidance although they seem to be susceptible to pneumococcal disease. ${ }^{13,14}$ Pneumonia is also the most common cause of death in patients with acute stroke,,$^{15}$ and it occurs more frequently than expected in dementia patients, ${ }^{7,16}$ and in patients with solid cancers. ${ }^{11,17,18}$

Given the uncertainty regarding the effectiveness of pneumococcal vaccination, ${ }^{19}$ and in the presence of increasing morbidity due to pneumonia, GPs need to be able to identify and closely monitor those patients at highest risk of pneumonia. For example, such patients might benefit from earlier intervention with antibiotics when they present to their GP with a chest infection. ${ }^{20}$ Better understanding about high-risk groups for pneumonia could also help inform future development of an effective vaccine to prevent pneumonia.

The main aim of this study is to identify additional independent risk factors for community-acquired pneumonia, which could potentially be used in clinical practice to guide treatment decisions.

\section{METHOD}

\section{Study design and setting}

A nested case-control study was conducted using general practices in the UK contributing to the QRESEARCH database (version 11, downloaded August 2006). The study period was the 10 years between 1 January 1996 and 31 December 2005.

\section{Study population}

An open cohort of patients registered at any time between 1 January 1996 and 31 December 2005, excluding temporary residents, was identified. For each patient, a left censor date was determined, which was the latest of the start of the study: 1 January 1996; the date of patient registration with the practice; or the date of the installation of the EMIS computer system. A right censor date was also defined, which was the earliest of the following: date of diagnosis of the outcome of interest; date of death; date of leaving the practice; date of the latest download of data; or 31 December 2005.

\section{Cases of pneumonia}

Patients with an incident diagnosis of pneumonia were identified - that is, patients with a first diagnosis during the 10-year study period (a list of diagnostic codes is available from the authors). Patients with a postmortem diagnosis were included as cases, but patients with a diagnosis prior to their entry into the cohort were excluded.

\section{Selection of controls}

Each case was matched to five controls who were

\section{How this fits in}

Patients with diabetes, chronic heart disease, chronic renal disease, chronic

respiratory disease, asplenia, cerebrospinal fluid shunt, chronic liver disease, sickle cell disease or coeliac disease, cochlear implant, HIV/AIDS, or

immunosuppression are at increased risk of invasive pneumococcal disease

and therefore are recommended by the Department of Health for pneumococcal vaccination in England. Patients with other conditions including stroke or

transient ischaemic attack, rheumatoid arthritis, Parkinson's disease, cancers,

multiple sclerosis, dementia, and osteoporosis also have about two- to threefold increase of risk of all causes community-acquired pneumonia and these conditions therefore should be considered as a high-risk patient group.

alive and registered with the practice where the case was registered at the time of diagnosis of each case. Controls were matched on age at index date (to within 1 year), sex, practice, and calendar time. Selection of controls was made without replacement. Controls were allocated an index date, which was the date on which their matched case was first diagnosed with pneumonia.

Patients aged $>5$ years were included in the analysis if they had at least 5 years of electronic health records available. Children $\leq 5$ years old were included in the analysis if they had complete health records since their birth. This was to ensure the data for vaccinations, prescriptions, and morbidity were as complete as possible over a 5-year period.

\section{Risk groups from current guidance}

'Established risk factors' were based on those patients identified as being at high risk of invasive pneumococcal disease according to the Chief Medical Officer's guidance for 2006. ${ }^{21}$ The following diseases were included: diabetes, chronic heart disease, chronic renal disease, chronic respiratory disease, asplenia, cerebrospinal fluid shunt, chronic liver disease, sickle cell or coeliac disease, cochlear implant, HIV/AIDS, and immunosuppression. Immunosuppression did not include patients already identified as being at high risk due to the other diseases in the list.

In addition, the risk was estimated in patients with chronic heart disease but without ischaemic heart disease, in patients with treated asthma, and in patients with asthma but no evidence of treatment ('untreated asthma'). Asthma treatment was defined as at least one prescription for a $\beta$ agonist and/or at least one inhaled steroid within the preceding 12 months.

\section{New potential risk groups}

The risk of pneumonia was determined in patients with other morbidities including the following: stroke or transient ischaemic attack, rheumatoid arthritis, 
Parkinson's disease, five common cancers (breast, colon, gastric, lung, prostate), multiple sclerosis, dementia, osteoporosis, and osteoarthritis.

These diseases were chosen either because they limit the mobility of patients, which might in turn increase the risk of pneumonia, or because they tend to be associated with immunosuppression.

Patients were considered to be in a current or new disease risk group if they had an appropriate Read code group in their electronic health record before the date of diagnosis of pneumonia, for cases, or before the matched index date, for controls.

\section{Statistical analysis}

All the available cases on the QRESEARCH database who met the inclusion criteria were used, in order to maximise the power of the study. Five matched controls were used per patient, since using more controls than this does not tend to increase the study power. ${ }^{22}$ In order to detect an odds ratio (OR) of 1.50 (which was predefined as being clinically important) at $1 \%$ significance with $80 \%$ power for a condition that occurs in $0.5 \%$ of controls, a sample size of 13500 cases and 67500 controls would be needed.

Conditional logistic regression was used to estimate OR with $95 \%$ confidence intervals (Cls) for pneumonia. A number of different models were used. First, the unadjusted OR for risk of pneumonia was determined for each of the disease risk groups (both current and potential). Then the OR associated with each disease risk group was determined, adjusting for the potential confounding effects of material deprivation (Townsend deprivation score in fifths based on the output area associated with the patient's postcode), smoking status (current smoker, not current smoker, smoking not recorded), use of influenza vaccine in the 12 months prior to the index date, and number of years of electronic data available prior to the index date (categorised as 5, 6, 7, 8, 9, $\geq 10$ years). All current disease groups were also adjusted for, and any new potential disease groups that had an unadjusted $\mathrm{OR} \geq 1.5$ were included. As patients aged 5-64 years are not recommended for routine pneumococcal vaccination, the same analyses were performed restricted to such cases and controls.

An additional model included pneumococcal vaccination (categorised as: no recorded pneumococcal vaccination in last 5 years; vaccinated $\geq 49$ months ago; vaccinated $12-48$ months ago;

Table 1. Distribution of diagnoses with the pneumonia outcome.

\begin{tabular}{|c|c|c|c|c|c|}
\hline & & $\begin{array}{c}\text { Cases } \\
\text { unrestricted, } n\end{array}$ & $\begin{array}{l}\% \text { of total cases } \\
(n=34098)\end{array}$ & $\begin{array}{l}\text { Cases restricted } \\
\text { to } 5 \text { years of records, } n\end{array}$ & $\begin{array}{c}\% \text { of total cases } \\
(n=17172)\end{array}$ \\
\hline $\mathrm{H} 2$ & Pneumonia and influenza & 814 & 2.4 & 379 & 2.2 \\
\hline $\mathrm{H} 21$ & Lobar (pneumococcal) pneumonia & 3083 & 9.0 & 1733 & 10.1 \\
\hline $\mathrm{H} 21-1$ & Chest infection - pneumococcal pneumonia & 90 & 0.3 & 46 & 0.3 \\
\hline$\underline{\mathrm{H} 22}$ & Other bacterial pneumonia & 359 & 1.1 & 221 & 1.3 \\
\hline $\mathrm{H} 22-1$ & Chest infection - other bacterial pneumonia & 137 & 0.4 & 86 & 0.5 \\
\hline H223 & Pneumonia due to streptococcus & 166 & 0.5 & 86 & 0.5 \\
\hline $\mathrm{H} 22 \mathrm{yz}$ & Pneumonia due to bacteria NOS & 597 & 1.8 & 318 & 1.9 \\
\hline $\mathrm{H} 22 \mathrm{z}$ & Bacterial pneumonia NOS & 1072 & 3.1 & 709 & 4.1 \\
\hline $\mathrm{H} 23-1$ & Chest infection - pneumonia organism OS & 2 & 0.0 & 0 & 0 \\
\hline $\mathrm{H} 25$ & Bronchopneumonia due to unspecified organism & 3872 & 11.4 & 1652 & 9.6 \\
\hline$\underline{\mathrm{H} 25-1}$ & Chest infection - unspecified bronchopneumonia & 900 & 2.6 & 330 & 1.9 \\
\hline $\mathrm{H} 26$ & Pneumonia due to unspecified organism & 12569 & 36.9 & 6160 & 35.9 \\
\hline$\underline{\mathrm{H} 260}$ & Lobar pneumonia due to unspecified organism & 5366 & 15.7 & 2706 & 15.8 \\
\hline $\mathrm{H} 261$ & Basal pneumonia due to unspecified organism & 1580 & 4.6 & 855 & 5.0 \\
\hline$\underline{\mathrm{H} 262}$ & Postoperative pneumonia & 61 & 0.2 & 40 & 0.2 \\
\hline $\mathrm{H} 270$ & Influenza with pneumonia & 81 & 0.2 & 29 & 0.2 \\
\hline $\mathrm{H} 270-1$ & Chest infection - influenza with pneumonia & 9 & 0.0 & 3 & 0.0 \\
\hline$\underline{\mathrm{H} 2700}$ & Influenza with bronchopneumonia & 67 & 0.2 & 20 & 0.1 \\
\hline $\mathrm{H} 2701$ & Influenza with pneumonia, influenza virus identified & 2 & 0.0 & 2 & 0.0 \\
\hline$\underline{\mathrm{H} 270 \mathrm{z}}$ & Influenza with pneumonia NOS & 18 & 0.1 & 9 & 0.1 \\
\hline $\mathrm{H} 28$ & Atypical pneumonia & 1301 & 3.8 & 663 & 3.9 \\
\hline$\underline{\mathrm{H} 2 \mathrm{y}}$ & Other specified pneumonia or influenza & 290 & 0.9 & 160 & 0.9 \\
\hline $\mathrm{H} 2 \mathrm{z}$ & Pneumonia or influenza NOS & 1662 & 4.9 & 965 & 5.6 \\
\hline
\end{tabular}

NOS = not otherwise specified. 
vaccinated 15-365 days ago; and vaccinated 1-14 days ago).

Key analyses were repeated, restricted to cases and controls where the index date was prior to 2003 (the year in which pneumococcal vaccine was recommended to all patients aged $\geq 65$ years), and to cases and controls with at least 10 full years of electronic prescribing records available. The analyses were also repeated restricted to cases with lobar and pneumococcal pneumonia and their controls, as those diagnoses were most likely made on hospital discharge. STATA (version 10) was used for all the analyses. Given the large number of comparisons being undertaken, a $P$ value of 0.01 or less was considered statistically significant. A priori, an $\mathrm{OR} \geq 1.5$ was considered to be clinically important.

Missing data for smoking status and Townsend deprivation score were analysed as a separate category. As records for children younger than 15 years hardly contained information about smoking status, they were assumed to be non-smokers. The analyses were also repeated considering smoking status in children as not recorded.

\section{RESULTS}

\section{Incidence rates of pneumonia}

There were 443 QRESEARCH practices included in the analysis. Overall there were 34098 incident cases of pneumonia arising from 29605328 patient-years, giving an overall incidence rate of 115 per 100000 patient-years.

The incidence of pneumonia varied by year and age group, approximately doubling between 1996 and 2005 in all age groups and reaching an age-sexstandardised rate of 150 cases per 100000 in 2005. The incidence rate was highest in patients aged $\geq 75$ years, next highest in patients aged $0-4$ years, and lowest in patients aged 15-44 years. Of all the cases of pneumonia, $25 \%$ had lobar or pneumococcal pneumonia. The distribution of specific diagnoses in all cases with pneumonia is presented in Table 1 . There were 17172 cases with at least 5 years of prior data, and these were included in the remaining analyses. Of these 4485 (26\%) had lobar or pneumococcal pneumonia.

\section{Baseline characteristics of pneumonia cases and controls}

Table 2 shows baseline characteristics for cases with pneumonia and their matched controls. Cases and controls were well balanced with respect to the length of longitudinal records available prior to the index date. Smoking was more common among cases than controls, and there was a slight tendency

\begin{tabular}{|c|c|c|c|}
\hline Characteristics & $\begin{array}{c}\text { Cases } \\
(n=17172)\end{array}$ & $\begin{array}{c}\text { Controls } \\
(n=71 \text { 399) }\end{array}$ & $\begin{array}{c}\text { Adjusted }{ }^{a} \text { OR } \\
(95 \% \mathrm{Cl})\end{array}$ \\
\hline \multicolumn{4}{|l|}{ Sex, $n(\%)$} \\
\hline Males & $8714(50.7)$ & $36338(50.9)$ & \\
\hline Females & $8458(49.3)$ & $35061(49.1)$ & \\
\hline \multicolumn{4}{|l|}{ Age band, years, $n(\%)$} \\
\hline $0-4$ & 2949 (17.2) & $13934(19.5)$ & \\
\hline $5-14$ & $811(4.7)$ & $3028(4.2)$ & \\
\hline $15-44$ & $2173(12.7)$ & 7450 (10.4) & \\
\hline $45-64$ & 3124 (18.2) & $12905(18.1)$ & \\
\hline $65-74$ & $2662(15.5)$ & $11597(16.2)$ & \\
\hline$\geq 75$ & $5453(31.8)$ & $22485(31.5)$ & \\
\hline Median (IQR) months of electronic data available & $83(65-111)$ & $83(64-111)$ & \\
\hline \multicolumn{4}{|l|}{ Deprivation, $n$ (\%) } \\
\hline Townsend fifth 1 most affluent & $3322(19.3)$ & $14945(20.9)$ & 1.00 \\
\hline Townsend fifth 2 & 3269 (19.0) & $14593(20.4)$ & 1.00 (0.95 to 1.06$)$ \\
\hline Townsend fifth 3 & 3303 (19.2) & $13665(19.1)$ & $1.08(1.02$ to 1.15$)$ \\
\hline Townsend fifth 4 & 3224 (18.8) & $12449(17.4)$ & 1.18 (1.11 to 1.25$)$ \\
\hline Townsend fifth 5 most deprived & $3553(20.7)$ & $13123(18.4)$ & 1.27 (1.19 to 1.36$)$ \\
\hline Townsend missing & $501(2.9)$ & $2624(3.7)$ & \\
\hline \multicolumn{4}{|l|}{ Smoking status, ${ }^{\mathrm{b}} n$ (\%) } \\
\hline Non-smoker & $11999(69.9)$ & $52367(73.3)$ & 1.00 \\
\hline Smoker & 3299 (19.2) & $8883(12.4)$ & 1.61 (1.53 to 1.69$)$ \\
\hline Smoking status not recorded & $1875(10.9)$ & $10158(14.2)$ & \\
\hline Influenza vaccination in prior 12 months, $n$ (\%) & $6535(38.1)$ & $23997(33.6)$ & 1.39 (1.32 to 1.46$)$ \\
\hline Pneumococcal vaccination in prior 60 months, $n$ (\%) & $2821(16.4)$ & $10263(14.4)$ & $1.08(1.02$ to 1.14$)$ \\
\hline
\end{tabular}

${ }^{a}$ Adjusted for the confounding factors listed in the Table. ${ }^{b}$ Children $<15$ years old were considered as non-smokers. IQR = interquartile range. $\mathrm{OR}=$ odds ratio. 


\begin{tabular}{|c|c|c|c|c|}
\hline & $\begin{array}{c}\text { Cases }(n=17 \text { 172), } \\
n(\%)\end{array}$ & $\begin{array}{c}\text { Controls }(n=71 \text { 399), } \\
n(\%)\end{array}$ & $\begin{array}{l}\text { Unadjusted OR } \\
\quad(95 \% \mathrm{Cl})\end{array}$ & $\begin{array}{c}\text { Adjusted }{ }^{a} \mathrm{OR} \\
(95 \% \mathrm{Cl})\end{array}$ \\
\hline \multicolumn{5}{|l|}{ Current risk factors } \\
\hline Diabetes & $1344(7.8)$ & $3847(5.4)$ & 1.54 (1.44 to 1.65$)$ & 1.36 (1.27 to 1.47$)$ \\
\hline Chronic heart disease & 3239 (18.9) & 8585 (12.0) & 1.91 (1.81 to 2.00$)$ & 1.63 (1.54 to 1.72$)$ \\
\hline Ischaemic heart disease & $2329(13.6)$ & $6984(9.8)$ & 1.54 (1.46 to 1.63$)$ & \\
\hline CHD, no IHD & $910(5.3)$ & $1604(2.2)$ & 2.53 (2.31 to 2.76$)$ & \\
\hline Chronic renal disease & $203(1.2)$ & $386(0.5)$ & 2.15 (1.81 to 2.56$)$ & 1.72 (1.43 to 2.07$)$ \\
\hline Chronic respiratory disease & $4468(26.0)$ & $8843(12.4)$ & 2.62 (2.51 to 2.73 ) & 2.42 (2.31 to 2.53 ) \\
\hline Treated asthma & 2329 (13.6) & $4043(5.7)$ & 2.65 (2.51 to 2.81$)$ & \\
\hline Untreated asthma & $504(2.9)$ & $1689(2.4)$ & 1.19 (1.07 to 1.32$)$ & \\
\hline Asplenia & $55(0.3)$ & $81(0.1)$ & 2.88 (2.04 to 4.06$)$ & 2.58 (1.80 to 3.71$)$ \\
\hline CSF shunt & $11(0.1)$ & $20(0.0)$ & 2.24 (1.07 to 4.71$)$ & 2.17 (1.00 to 4.69$)$ \\
\hline Chronic liver disease & $94(0.5)$ & $175(0.2)$ & 2.24 (1.74 to 2.89$)$ & 1.87 (1.43 to 2.44$)$ \\
\hline Sickle cell or coeliac disease & $55(0.3)$ & $85(0.1)$ & 2.65 (1.87 to 3.75$)$ & 2.42 (1.68 to 3.49$)$ \\
\hline Cochlear implant & $0(0.0)$ & $3(0.0)$ & & \\
\hline HIV/AIDS & $22(0.1)$ & $31(0.0)$ & 2.71 (1.50 to 4.90$)$ & 2.48 (1.34 to 4.58$)$ \\
\hline Immunosuppressed & $776(4.5)$ & $2910(4.1)$ & $1.12(1.03$ to 1.21$)$ & 1.40 (1.26 to 1.55$)$ \\
\hline \multicolumn{5}{|l|}{ New potential risk factors } \\
\hline Stroke or TIA & $1454(8.5)$ & $3583(5.0)$ & $1.86(1.74$ to 1.99$)$ & 1.63 (1.52 to 1.75$)$ \\
\hline Rheumatoid arthritis & $387(2.3)$ & $821(1.1)$ & 2.02 (1.79 to 2.29$)$ & 1.84 (1.62 to 2.10$)$ \\
\hline Parkinson's disease & $230(1.3)$ & $513(0.7)$ & 1.87 (1.60 to 2.19$)$ & 1.82 (1.53 to 2.15$)$ \\
\hline Multiple sclerosis & $85(0.5)$ & $112(0.2)$ & 3.20 (2.40 to 4.26$)$ & 3.63 (2.70 to 4.88 ) \\
\hline Dementia & $385(2.2)$ & $674(0.9)$ & 2.41 (2.11 to 2.75$)$ & 2.45 (2.13 to 2.81$)$ \\
\hline Osteoporosis & $650(3.8)$ & $1578(2.2)$ & 1.84 (1.67 to 2.03$)$ & 1.57 (1.41 to 1.74$)$ \\
\hline Osteoarthritis & $2310(13.5)$ & $8932(12.5)$ & $1.12(1.06$ to 1.18$)$ & \\
\hline Any cancer & $1151(6.7)$ & $2976(4.2)$ & 1.70 (1.58 to 1.82$)$ & 1.42 (1.30 to 1.56$)$ \\
\hline Breast cancer & $190(1.1)$ & $667(0.9)$ & 1.17 (0.99 to 1.38$)$ & \\
\hline Colon cancer & $107(0.6)$ & $361(0.5)$ & 1.23 (0.99 to 1.53$)$ & \\
\hline Lung cancer & $107(0.6)$ & $98(0.1)$ & 4.73 (3.58 to 6.25$)$ & \\
\hline Gastric cancer & $16(0.1)$ & $48(0.1)$ & 1.38 (0.78 to 2.44$)$ & \\
\hline Prostate cancer & $200(1.2)$ & $617(0.9)$ & 1.38 (1.17 to 1.63$)$ & \\
\hline
\end{tabular}

${ }^{a}$ Model includes all current risk factors and any new risk factors with unadjusted odds ratio $>1.5$, smoking status, Townsend score in quintiles, use of influenza vaccine in last 12 months, use of pneumococcal vaccine in last 5 years (1-14 days, 2-52 weeks, 12-48 months, 49-60 months), number of years of medical records data $(5,6,7,8,9, \geq 10)$. CSF = cerebrospinal fluid. $C H D=$ coronary heart disease. $I H D=$ ischaemic heart disease. OR =odds ratio. $T I A=$ transient ischaemic attack.

Figure 1. Risk of pneumonia in patients of all ages. for cases to be from more deprived areas than controls. Uptake of influenza vaccination in the

$\begin{array}{llll} & & \text { Adjusted odds ratios and } 95 \% \text { confidence intervals } \\ \text { Diagnosed with } & \mathrm{N} \text { cases/controls } & \mathrm{OR}(95 \% \mathrm{Cl}) \\ \text { Diabetes } & 1334 / 3847 & 1.36(1.27 \text { to } 1.47) \\ \text { Heart disease } & 3239 / 8585 & 1.63(1.54 \text { to } 1.72) \\ \text { Renal disease } & 203 / 386 & 1.72(1.43 \text { to } 2.07) \\ \text { Respiratory disease } & 4468 / 8843 & 2.42(2.31 \text { to } 2.53) \\ \text { Asplenia } & 55 / 81 & 2.58(1.80 \text { to } 3.71) \\ \text { Chronic liver disease } & 94 / 17 & 1.87(1.43 \text { to } 2.44) \\ \text { Sickle cell/Coel. disease } & 55 / 85 & 2.42(1.68 \text { to } 3.49) \\ \text { HIV/AIDS } & 22 / 31 & 2.48(1.34 \text { to } 4.58) \\ \text { Immunosuppressed } & 776 / 2910 & 1.40(1.26 \text { to } 1.55) \\ \text { Stroke or TIA } & 1454 / 3583 & 1.63(1.52 \text { to } 1.75 \\ \text { Rheumatoid athritis } & 387 / 821 & 1.84(1.62 \text { to } 2.10) \\ \text { Parkinson's disease } & 230 / 513 & 1.82(1.53 \text { to } 2.15) \\ \text { Multiple sclerosis } & 85 / 112 & 3.63(2.70 \text { to } 4.88) \\ \text { Dementia } & 385 / 674 & 2.45(2.13 \text { to } 2.81) \\ \text { Osteoporosis } & 650 / 1578 & 1.57(1.41 \text { to } 1.74) \\ \text { Any cancer } & 1151 / 2976 & 1.42(1.30 \text { to } 1.56) \\ & & \end{array}$

preceding 12 months was also marginally higher in cases than controls.

\section{Risks of pneumonia according to disease risk groups}

Figure 1 and Table 3 show the number of cases and controls with diagnoses for diseases in the established risk groups, and in the potential new risk groups prior to the date of diagnosis of pneumonia in cases, and to the equivalent index date in controls. Almost half of the cases (46\%) had been diagnosed with at least one of the diseases in the existing risk groups, compared to $29 \%$ of the controls. The unadjusted ORs for all of the current risk factor diseases were $>1.5$, apart from in the immunosuppressed patient group, where the unadjusted OR was $1.12(95 \% \mathrm{Cl}=1.03$ to 1.21$)$.

For the new potential risk factors, the proportion of cases diagnosed with any of these diseases was significantly higher than among controls. Most of the unadjusted OR were $>1.5$. Among the cancer patients, 
those with lung cancer had the highest unadjusted OR for pneumonia (unadjusted OR: $4.73,95 \% \mathrm{Cl}=3.58$ to 6.25). Multiple sclerosis showed the next highest risk of pneumonia (unadjusted OR: $3.20,95 \% \mathrm{Cl}=2.40$ to 4.26). As the unadjusted OR for osteoarthritis was only $1.12(95 \% \mathrm{Cl}=1.06$ to 1.18$)$, it was excluded from further analysis. More than one-fifth of cases $(21.2 \%)$ had been diagnosed with at least one of the potential risk factors (stroke or transient ischaemic attack [TIA], rheumatoid arthritis, Parkinson's disease, multiple sclerosis, dementia, osteoporosis, or any type of cancer) compared with $12.6 \%$ of controls.

Adjustment for a number of potential confounding variables tended to reduce the $\mathrm{OR}$, with the exception of the immunosuppressed, multiple sclerosis, and dementia groups. The adjusted ORs for all current and potential risk groups were greater than 1.5, except for in the diabetes, immunosuppressed, and any cancer groups. The highest adjusted ORs were for multiple sclerosis, HIV/AIDS, and asplenia.

Table 4 shows the numbers of patients diagnosed with only a current risk group disease, only a new potential risk group disease, and with diseases from both risk groups. Out of 7894 cases diagnosed with a current risk group disease, 2696 patients (34\%) were also diagnosed with at least one of the new potential risk group diseases, and out of 20985 controls with a current risk group disease, 5957 (28\%) also had a new risk group disease. For example, most of the cancer patients $(97.6 \%$ of cases with cancer and $97.0 \%$ of controls) fall into the immunosuppressed group. The adjusted risk of pneumonia in patients with one or more current risk factor conditions but no new risk factors was 2.3-fold increased (OR: $2.33,95 \% \mathrm{Cl}=$ 2.23 to 2.44) compared with patients with no current or new risk factors. In patients with one or more new potential risk factor conditions (excluding osteoarthritis) and not diagnosed with diseases from

\begin{tabular}{|c|c|c|c|c|}
\hline & $\begin{array}{c}\text { Cases, } \\
n(\%)\end{array}$ & $\begin{array}{c}\text { Controls, } \\
n(\%)\end{array}$ & $\begin{array}{l}\text { Unadjusted OR } \\
\qquad(95 \% \mathrm{Cl})\end{array}$ & $\begin{array}{c}\text { Adjusted }{ }^{a} \text { OR } \\
(95 \% \mathrm{Cl})\end{array}$ \\
\hline \multicolumn{5}{|c|}{ All patients (17 172 cases and 71399 controls) } \\
\hline \multicolumn{5}{|c|}{ Conditions from current and new risk factor lists } \\
\hline No current or new risk factors & 8338 (48.6) & $47385(66.4)$ & 1.00 & 1.00 \\
\hline Current risk factors only & $5198(30.3)$ & $15028(21.1)$ & 2.48 (2.37 to 2.59$)$ & 2.33 (2.23 to 2.44$)$ \\
\hline New risk factors only & $940(5.5)$ & $3029(4.2)$ & 2.51 (2.31 to 2.72 ) & 2.44 (2.24 to 2.65$)$ \\
\hline Current and new risk factors & $2696(15.7)$ & $5957(8.3)$ & 3.80 (3.57 to 4.04$)$ & 3.59 (3.38 to 3.82$)$ \\
\hline \multicolumn{5}{|c|}{ Conditions from current risk factor list } \\
\hline Any current risk factor & $7894(46.0)$ & $20985(29.4)$ & 2.43 (2.34 to 2.53$)$ & 2.29 (2.20 to 2.39$)$ \\
\hline One condition & $5878(34.2)$ & $17431(24.4)$ & 2.18 (2.09 to 2.27$)$ & 2.08 (1.99 to 2.17$)$ \\
\hline Two conditions & $1680(9.8)$ & $3142(4.4)$ & 3.93 (3.66 to 4.21$)$ & 3.63 (3.38 to 3.90$)$ \\
\hline Three or more conditions & $336(2.0)$ & $411(0.6)$ & 6.12 (5.26 to 7.12$)$ & 5.64 (4.84 to 6.58$)$ \\
\hline \multicolumn{5}{|c|}{ Conditions from current and new risk factor lists } \\
\hline Any risk factor & $8834(51.4)$ & 24014 (33.6) & 2.71 (2.60 to 2.82$)$ & 2.56 (2.45 to 2.68$)$ \\
\hline One condition & $4736(27.6)$ & $15280(21.4)$ & 2.26 (2.16 to 2.36$)$ & 2.16 (2.06 to 2.26$)$ \\
\hline Two conditions & 2786 (16.2) & $6669(9.3)$ & 3.57 (3.37 to 3.79$)$ & 3.37 (3.17 to 3.59 ) \\
\hline Three or more conditions & $1312(7.6)$ & $2064(2.9)$ & 5.85 (5.39 to 6.36$)$ & 5.50 (5.05 to 5.98$)$ \\
\hline \multicolumn{5}{|c|}{ Patients aged $5-64$ years (6108 cases and $23-383$ controls) } \\
\hline \multicolumn{5}{|c|}{ Conditions from current and new risk factor lists } \\
\hline No current or new risk factors & $3807(62.3)$ & $18487(79.1)$ & 1.00 & 1.00 \\
\hline Current risk factors only & $1794(29.4)$ & $3974(17.0)$ & 2.30 (2.15 to 2.47$)$ & 1.96 (1.82 to 2.11$)$ \\
\hline New risk factors only & $166(2.7)$ & $376(1.6)$ & 2.49 (2.05 to 3.02$)$ & 2.32 (1.91 to 2.82$)$ \\
\hline Current and new risk factors & $341(5.6)$ & $546(2.3)$ & 3.65 (3.15 to 4.24$)$ & 3.14 (2.69 to 3.66$)$ \\
\hline \multicolumn{5}{|c|}{ Conditions from current risk factor list } \\
\hline Any current risk factor & $2135(35.0)$ & 4520 (19.3) & 2.36 (2.21 to 2.52$)$ & 2.01 (1.87 to 2.15$)$ \\
\hline One condition & 1868 (30.6) & 4175 (17.9) & 2.23 (2.09 to 2.38$)$ & 1.94 (1.80 to 2.09$)$ \\
\hline Two conditions & 229 (3.75) & $311(1.33)$ & 4.10 (3.42 to 4.92$)$ & 3.05 (2.52 to 3.70$)$ \\
\hline Three or more conditions & $38(0.62)$ & $34(0.15)$ & $6.83(4.22$ to 11.0$)$ & 5.25 (3.21 to 8.58$)$ \\
\hline \multicolumn{5}{|c|}{ Conditions from current and new risk factor lists } \\
\hline Any risk factor & 2301 (37.7) & 4896 (20.9) & 2.44 (2.29 to 2.61$)$ & 2.10 (1.96 to 2.24$)$ \\
\hline One condition & $1735(28.4)$ & 4041 (17.3) & 2.20 (2.05 to 2.36$)$ & 1.93 (1.80 to 2.08$)$ \\
\hline Two conditions & $468(7.7)$ & $756(3.2)$ & 3.64 (3.20 to 4.13$)$ & 3.01 (2.63 to 3.44$)$ \\
\hline Three or more conditions & $98(1.6)$ & $99(0.4)$ & 6.45 (4.79 to 8.67$)$ & 5.14 (3.79 to 6.97$)$ \\
\hline
\end{tabular}

aAll models include smoking status, Townsend score in quintiles, use of influenza vaccine in last 12 months, use of pneumococcal vaccine in last 5 years (1-14 days, 2-52 weeks, 12-48 months, 49-60 months), number of years of medical records data $(5,6,7,8,9, \geq 10)$. OR = odds ratio. 


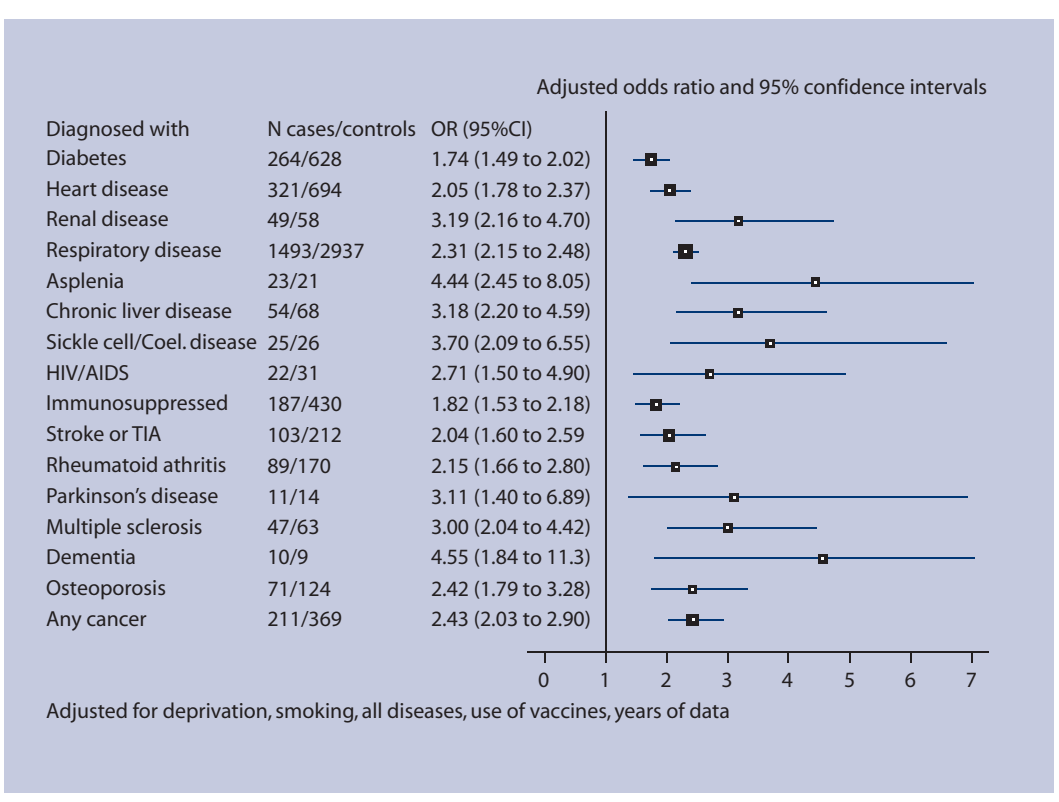

Figure 2. Risk of pneumonia in patients aged 5-64 years. the current risk group, the risk was almost 2.5-fold increased (OR: $2.44,95 \% \mathrm{Cl}=2.24$ to 2.65 ) after adjusting for smoking, deprivation, use of influenza vaccine, use of pneumococcal vaccine, and years of medical records.

Table 4 also show how multiple conditions affect the risk of pneumonia: patients with three or more conditions have a risk almost three times as high as patients with only one condition.

\section{Restricted analyses}

The analyses were repeated on patients aged 5-64 years. The results were similar to those in patients of all ages. The risk of pneumonia in those with one or more current risk factor diseases and no new risk factor disease adjusted for the confounding variables was twofold increased (OR: $1.96,95 \% \mathrm{Cl}=$ 1.82 to 2.11 ), and in those with one or more diseases from the potential risk factor list (excluding osteoarthritis) and not diagnosed with any of the current risk group diseases, it was 2.3-fold increased (OR: $2.32,95 \% \mathrm{Cl}=1.91$ to 2.82 ). These results are shown in Figure 2 and Table 4.

The analyses also showed similar results to the analyses performed for the whole sample when restricted to: patients aged $\geq 65$ years; patients with pneumonia diagnosed before 2003; and patients with lobar or pneumococcal pneumonia. The increased risk of pneumonia for those patients with at least one of the diseases from the current risk factor list was approximately the same (OR ranged from 2.29 for patients with lobar pneumonia to 2.32 for patients with

\begin{tabular}{|c|c|c|c|}
\hline & $\begin{array}{c}\text { Cases, } \\
n(\%)\end{array}$ & $\begin{array}{c}\text { Controls, } \\
n(\%)\end{array}$ & $\begin{array}{l}\text { Adjusted }{ }^{a} \text { OR } \\
(95 \% \mathrm{Cl})\end{array}$ \\
\hline \multicolumn{4}{|c|}{ Timing of pneumococcal vaccination before pneumonia diagnosis } \\
\hline \multicolumn{4}{|c|}{ Patients with $\geq 5$ years of medical records (17 172 cases and 71399 controls) } \\
\hline No recorded use in last 5 years & $14351(83.6)$ & $61136(85.6)$ & 1.00 \\
\hline$\geq 49$ months ago & $476(2.8)$ & $1525(2.1)$ & $1.11(0.98$ to 1.25$)$ \\
\hline $12-48$ months ago & $1604(9.3)$ & $5457(7.6)$ & $1.02(0.95$ to 1.10$)$ \\
\hline $15-365$ days ago & $715(4.2)$ & $3137(4.4)$ & $0.83(0.76$ to 0.92$)$ \\
\hline $1-14$ days ago & $26(0.2)$ & $144(0.2)$ & $0.67(0.43$ to 1.04$)$ \\
\hline \multicolumn{4}{|c|}{ Patients with $\geq 10$ years of medical records (6642 cases and 27294 controls) } \\
\hline No recorded use in last 10 years & $5429(81.7)$ & $23380(85.7)$ & 1.00 \\
\hline$\geq 61$ months ago & $491(7.4)$ & $1287(4.7)$ & $1.18(1.02$ to 1.37$)$ \\
\hline $49-60$ months ago & $106(1.6)$ & $346(1.3)$ & $0.93(0.72$ to 1.19$)$ \\
\hline 12-48 months ago & $402(6.1)$ & $1266(4.6)$ & $1.06(0.91$ to 1.23$)$ \\
\hline $15-365$ days ago & $202(3.0)$ & $972(3.6)$ & $0.71(0.59$ to 0.86$)$ \\
\hline $1-14$ days ago & $12(0.2)$ & $43(0.2)$ & 0.95 (0.48 to 1.87$)$ \\
\hline \multicolumn{4}{|c|}{ Timing of pneumococcal vaccination before diagnosis of lobar or pneumococcal pneumonia } \\
\hline \multicolumn{4}{|c|}{ Patients with $\geq 5$ years of medical records ( 4485 cases and 18596 controls) } \\
\hline No recorded use in last 5 years & $3792(84.6)$ & $16135(86.8)$ & 1.00 \\
\hline$\geq 49$ months ago & $124(2.8)$ & $351(1.9)$ & 1.23 (0.97 to 1.56$)$ \\
\hline $12-48$ months ago & $387(8.6)$ & $1279(6.9)$ & $1.05(0.91$ to 1.21$)$ \\
\hline $15-365$ days ago & $173(3.9)$ & $794(4.3)$ & $0.82(0.67$ to 1.00$)$ \\
\hline $1-14$ days ago & $9(0.2)$ & $37(0.2)$ & 0.98 (0.45 to 2.14$)$ \\
\hline \multicolumn{4}{|c|}{ Patients with $\geq 12$ months of medical records ( 7502 cases and 34941 controls) } \\
\hline No recorded use in last 12 months & $7199(96.0)$ & $33615(96.2)$ & 1.00 \\
\hline $15-365$ days ago & $290(3.87)$ & $1260(3.61)$ & $0.88(0.76$ to 1.02$)$ \\
\hline $1-14$ days ago & $13(0.17)$ & $66(0.19)$ & 0.76 (0.41 to 1.43$)$ \\
\hline
\end{tabular}

${ }^{a} \mathrm{ORs}$ (odds ratios) are adjusted for one or more current risk factors, one or more new potential risk factors, smoking status,

Townsend score in quintiles, use of influenza vaccine in last 12 months, number of years of medical records data $(5,6,7,8,9,10)$. 
pneumonia diagnosed before 2003). The increased risk of pneumonia for patients with at least one disease from the new potential risk factor list and without diseases from the current risk factor group varied slightly (OR ranged from 1.94 for patients with lobar pneumonia to 2.50 for patients aged $\geq 65$ years and patients diagnosed before 2003).

\section{Pneumococcal vaccination}

Table 5 shows the number of cases and controls vaccinated with pneumococcal vaccine. Only $16.4 \%$ of cases and $14.4 \%$ of controls had records of pneumococcal vaccination in the last 5 years. Among the patients with at least 10 years of medical records, the proportion of cases who had been vaccinated in the last 10 years was $18.3 \%$, and the proportion of controls was $14.3 \%$. Table 5 shows results from adjusted analyses for time since the last vaccination in individuals with at least 5 and 10 years of data. There was a significantly lower risk of pneumonia in patients who had been vaccinated between 15 and 365 days previously, compared with those not vaccinated in the last 5 years (OR $0.83,95 \% \mathrm{Cl}=0.76$ to 0.92 ), but not in patients vaccinated more than 12 months earlier.

Table 5 also shows the results of the analysis regarding the use of pneumococcal vaccine, but restricted to patients with lobar or pneumococcal pneumonia. The adjusted OR were similar to those for all pneumonia cases, although they were not statistically significant at the $1 \%$ significance level.

All the analyses were performed assuming missing smoking status for children aged $<15$ years as nonsmokers. Exactly the same results were obtained for all analyses, assuming smoking status for children as not recorded.

\section{DISCUSSION}

\section{Summary of main findings}

This is a large population-based case-control study designed to determine risk factors for communityacquired pneumonia. Overall, the study has shown that diagnoses of pneumonia are about two to three times more common in individuals in any of the specified clinical risk groups (both existing and new risk groups) than in individuals without these conditions. Similar results were obtained for subgroup analyses on patients with more specific diagnoses of lobar or pneumococcal pneumonia.

The increased risk of all-cause pneumonia among patients in existing risk groups persisted despite adjustment for the potential confounding effects of deprivation, smoking, and influenza and pneumococcal vaccination (OR: 2.29 in patients with one or more current risk factor diseases). This analysis, therefore, reinforces existing risk groups which include patients with diabetes, chronic heart disease, chronic renal disease, chronic respiratory disease, asplenia, cerebrospinal fluid shunt, chronic liver disease, sickle cell disease, coeliac disease, cochlear implant, HIV/AIDS, or immunosuppression.

The new risk groups identified in this study include patients with stroke or transient ischaemic attack, rheumatoid arthritis, Parkinson's disease, cancers, multiple sclerosis, dementia, and osteoporosis. Overall, a 2.5-fold increased risk of all-cause pneumonia was found among patients with one or more of these new risk factors, taking into account known risk factors and potential confounding variables (OR: 2.44). Patients with lung cancer and multiple sclerosis have particularly high increased risk of pneumonia, with fivefold and threefold increased risks respectively. The magnitude of these risks exceeds that observed for the majority of existing risk groups.

The study also showed some effectiveness of the pneumococcal vaccine, decreasing the risk of pneumonia by $17 \%$ (OR: $0.83,95 \% \mathrm{Cl}=0.76$ to 0.92 ), and only if the vaccine was administrated within the year before the index date. This effect is not large and is not protective enough for the general population; therefore, taking into account other risk factors is essential in preventing pneumonia. A similar conclusion was reached in a systematic review and meta-analysis based on 22 randomised control trials showing no significant preventive effect of pneumococcal vaccination..$^{23}$

This is a unique study in the community setting looking at the effect of comorbidities on the risk of pneumonia. British Thoracic Society guidelines recognised such conditions as asplenia, sickle cell and coeliac disease, renal disease, heart disease, lung disease, liver disease, diabetes, and immunosuppression due to HIV infection; ${ }^{1}$ and these diseases are included in the vaccine guidelines. This study has not only confirmed that patients with current risk group conditions have an increased risk of pneumonia, but has also demonstrated that there is an additional group of patients who are not recommended for pneumococcal vaccination but have an increased risk of pneumonia.

\section{Strengths and limitations of the study}

The study has several strengths. The QRESEARCH database has been validated (http://www.qresearch. org) and covers a large representative population from primary care, so the results are likely to be generalisable to the rest of the UK. As the study is based on computer-recorded prescribing and morbidity data collected prospectively, it was possible to include all eligible patients (including those who had died), thereby avoiding selection bias.

Matching of controls to cases on age, sex, calendar 
time, and practice removed confounding by these factors. The analysis was also adjusted for smoking, deprivation, and influenza and pneumococcal vaccinations, to minimise the potential confounding effects of these variables. In contrast to studies based on questionnaire or interview data, there is no recall bias, since information about the patient and morbidities, as well as exposure to pneumococcal vaccine, was prospectively recorded on computer before the diagnosis of pneumonia was made and so is unaffected by the pneumonia diagnosis itself. Any bias due to misclassification is likely to be minimal, because recording of clinical diagnosis and use of prescribed medications in general practice has been shown to have high levels of accuracy and completeness. ${ }^{24}$

The study had some limitations - information on certain risk factors for pneumonia such as use of alcohol is less consistently recorded in patient electronic health records and so has not been included in the analysis. The study has, however, included liver disease, which could be viewed as a proxy for chronic alcohol use. As with all observational studies, there could be residual confounding which it is not possible to fully correct.

The increased risk of pneumonia in the previously identified and newly identified risk groups could be a reflection of consulting bias, where pneumonia is opportunistically diagnosed when patients consult for one of these conditions. However, given that pneumonia is a serious diagnosis, it is unlikely that such a diagnosis would be made by chance in a patient consulting for another reason.

The other limitation is that the diagnosis of pneumonia was recorded by a GP and quite often was not supported by chest X-ray examination. However, British Thoracic Society guidelines do not consider chest radiograph as a necessary investigation for such patients in the community, relying instead on clinical symptoms of pneumonia. ${ }^{1}$ However, a GP's knowledge of a patient's comorbidities might alter the likelihood of making the diagnosis of pneumonia. This is a potential source of diagnostic bias which cannot be controlled for.

\section{Comparison with existing literature}

The pneumonia incidence rates have increased over time, which is consistent with trends of hospital admissions for pneumonia, ${ }^{25}$ but contrasts with trends in incidence data reported by the Royal College of General Practitioners (RCGP), ${ }^{26}$ which have shown a consistent decline. More detailed comparisons, however, between QRESEARCH and RCGP data show that, when similar definitions of pneumonia are used, the rates are comparable, suggesting that some of the difference is due to differences in data capture and case definition (D Fleming, personal communication, 2007). The definitions of pneumonia in the present analyses, for example, include postmortem diagnoses and diagnoses entered retrospectively after discharge from hospital, whereas the RCGP data only include contemporaneous diagnoses made during GP consultations.

\section{Implications for clinical practice and future research}

In addition to confirming some 'established risk factors', this study has identified seven new independent risk factors for all-cause communityacquired pneumonia. The results of this study could help clinicians identify patients at higher risk of pneumonia and also help inform future vaccine development given the possible lack of efficacy of the 23-valent vaccine against pneumonia. Further research would be needed to determine whether these high-risk patient groups would benefit from early intervention with antibiotics in the event of a respiratory infection or during a flu epidemic.

\section{Funding body}

The project was funded by the Health Protection Agency.

\section{Ethics committee}

This project was approved by the QRESEARCH scientific board for approval and was notified to the Trent Multi Centre Research Ethics Committee, reference number MREC/03/4/021

\section{Competing interests}

Julia Hippisley-Cox is university professor and co-director of QRESEARCH - a not-for-profit organisation which specialises in the independent academic analysis and research of primary care health data. QRESEARCH is a joint venture between the University of Nottingham and EMIS (commercial supplier of $60 \%$ of primary care systems in use in the UK)

\section{Acknowledgements}

We acknowledge the contribution of Dr David Stables (medical director of EMIS) for expertise in creating and maintaining QRESEARCH, and to the EMIS practices that contribute data.

\section{Discuss this article}

Contribute and read comments about this article on the Discussion Forum: http://www.rcgp.org.uk/bjgp-discuss

\section{REFERENCES}

1. British Thoracic Society of Standards of Care Committee. BTS guidelines for the management of community acquired pneumonia in adults. Thorax 2001; 56(suppl 4): ivl-iv64.

2. British Thoracic Society of Standards of Care Committee. BTS guidelines for the management of community acquired pneumonia in childhood. Thorax 2002; 57(90001): i1-24.

3. Department of Health. Immunisation against infectious disease - the Green Book.

http://www.dh.gov.uk/en/Publichealth/Healthprotection/Immunisatio n/Greenbook/DH_4097254 (accessed 10 Aug 2009).

4. Fletcher M, Laufer D, McIntosh E, et al. Controlling invasive pneumococcal disease: is vaccination of at risk groups sufficient? J Clin Pract 2006; 60(4): 450-456.

5. Centers for Disease Control and Prevention (CDC). Recommendations of the Advisory Committee on Immunizations Practices (ACIP): use of vaccines and immune globulins in person with altered immunocompetence. MMWR 1993; 42(RR-4): 1-18.

6. Burman L, Norrby R, Trollfors B. Invasive pneumococcal infections: 
incidence, predisposing factors, and prognosis. Rev Infect Dis 1985; 7(2): 133-142.

7. Lipsky B, Boyko E, Inui T, Koepsell T. Risk factors for acquiring pneumococcal infections. Arch Intern Med 1986; 146(11): 2179-2185.

8. Centers for Disease Control and Prevention (CDC). Recommendations of the Advisory Committee on Immunizations Practices (ACIP): prevention of pneumococcal disease. MMWR 1997; 46(RR-8): 1-24.

9. Linnemann CJ, First M. Risk of pneumococcal infections in renal transplant patients. JAMA 1979; 241(24): 2619-2621.

10. Keller D, Breiman R. Preventing bacterial respiratory tract infections among persons infected with human immunodeficiency virus. Clin Infect Dis 1995; 21(suppl 1): S77-S83.

11. Almirall J, Bolibar I, Serra-Prat M, et al. New evidence of risk factors for community-acquired pneumonia: a population-based study. Eur Respir J 2008; 31(6): 1274-1284.

12. Pebody R, Hippisley-Cox J, Pringle M, et al. Uptake of pneumococcal polysaccharide vaccine in at-risk populations in England and Wales, 1999-2005. Epidemiol Infect 2008; 136(3):360-369.

13. Jokinen C, Heiskanen L, Juvonen H, et al. Incidence of communityacquired pneumonia in the population of four municipalities in Eastern Finland. Am J Epidemiol 1993; 137(9): 977-988.

14. Raad J, Peacock J. Septic arthritis in the adult caused by Streptococcus pneumoniae: a report of 4 cases and review of the literature. Semin Arthritis Rheum 2004; 34(2): 559-569.

15. Prass K, Braun J, Dirnagl U, et al. Stroke propagates bacterial aspiration to pneumonia in a model of cerebral ischemia. Stroke 2006; 37(10): 2607-2612.

16. Hak E, Bont J, Hoes A, Verheij T. Prognostic factors for serious morbidity and mortality from community-acquired lower respiratory tract infections among the elderly in primary care. Fam Pract 2005; 24(6): $377-383$
17. Kyaw M, Rose CJ, Fry A, et al. The influence of chronic illnesses on the incidence of invasive pneumococcal disease in adults. J Infect Dis 2005; 192(3): 377-386.

18. Kothe H, Bauer T, Marre R, et al. Outcome of community-acquired pneumonia: influence of age, residence status and antimicrobial treatment. Eur Respir J 2008; 32(1): 139-146.

19. Conaty S, Watson L, Dines J, Waugh N. The effectiveness of pneumococcal polysaccharide vaccines in adults: a systematic review of observational studies and comparison with results from randomized controlled trials. Vaccine 2004; 22(23-24): 3214-3224.

20. Dambrava PG, Torres A, Valles X, et al. Adherence to guidelines' empirical antibiotic recommendations and community-acquired pneumonia outcome. Eur Respir J 2008; 32(4): 892-901.

21. Department of Health. PL CMO (2005)1: The Pneumococcal Immunisation Programme for Older People and Risk Groups. London: Department of Health, 2009.

http://www.dh.gov.uk/en/Publicationsandstatistics/Lettersandcirculars /Professionalletters/Chiefmedicalofficerletters/DH_4107903 (accessed 10 Aug 2009).

22. Woodward M. Epidemiology: study design and data analysis. 2nd edn. London: Chapman \& Hall, 2005.

23. Huss A, Scott P, Stuck AE, et al. Efficacy of pneumococcal vaccination in adults: a meta-analysis. CMAJ 2009; 180(1): 48-58.

24. Nazareth I, King M, Haines A, et al. Accuracy of diagnosis of psychosis in general practice computer system. BMJ 1993; 307(6895): 32-34.

25. Hospital Episode Statistics online. Total number of emergency admissions to hospital where the diagnosis was pneumonia between 2002-03 and 2006-07. http://www.hesonline.nhs.uk (accessed 29 June 2009).

26. Royal College of General Practitioners, Birmingham Research Unit. Weekly return service annual report. Birmingham: RCGP, 2005. http://www.rcgp.org.uk/clinical_and_research/rsc/annual_reports.aspx (accessed 10 Aug 2009). 